\title{
Summary of the NACl literature review on the comparative effectiveness of subunit and split virus inactivated influenza vaccines in older adults
}

\author{
I Gemmill ${ }^{1,2}, \mathrm{~K}$ Young ${ }^{3}$ on behalf of the National Advisory Committee on Immunization (NACl)*
}

\begin{abstract}
Background: Subunit and split virus inactivated influenza vaccines (IIV) are two commonly used types of seasonal influenza vaccines in Canada. The comparative effectiveness of these two formulations is particularly relevant for older adults, as older adults have reduced influenza vaccine effectiveness and experience more severe influenza than younger adults.
\end{abstract}

Objective: To compare the vaccine effectiveness and immunogenicity of unadjuvanted, standard-dose subunit IIVs versus unadjuvanted, standard-dose split virus IIVs in adults 65 years of age and older.

Methods: An a priori written protocol based on rapid review methods was developed that included studies published in 2007 or later in the EMBASE, MEDLINE and ClinicalTrials.gov databases with terms used in the objective. Due to the small number of records returned, hand searches of reference lists were completed, the publication date limit was removed, three additional databases (the Cochrane Central Register of Controlled Trials, Scopus and Web of Science) were searched, and studies including adults 60 years of age and older were included. Data from included studies were extracted into evidence tables and quality assessments were completed. The results were synthesized narratively.

Results: Eight eligible studies were identified. In the three studies that assessed vaccine effectiveness of subunit and split virus IIVs, there were no statistically significant differences in vaccine effectiveness in adults 65 years of age and older against laboratory-confirmed infection with any influenza virus strain, or against laboratory-confirmed infection with influenza $A(H 1 N 1)$, $A(H 3 N 2)$ or B virus, specifically. In the five studies that assessed immunogenicity, the findings were not consistent and the overall quality of immunogenicity evidence was weak.

Conclusion: The National Advisory Committee on Immunization (NACl) concludes that there is insufficient evidence to determine significant differences in the vaccine effectiveness or immunogenicity of unadjuvanted, standard-dose subunit and split virus IIVs in adults 65 years of age and older (Grade I evidence).

Suggested citation: Gemmill I, Young K on behalf of the National Advisory Committee on Immunization (NACl). Summary of the $\mathrm{NACl}$ literature review on the comparative effectiveness of subunit and split virus inactivated influenza vaccines in older adults. Can Commun Dis Rep 2018;44(6):129-33.

https://doi.org/10.14745/ccdr.v44i06a02

Keywords: The National Advisory Committee on Immunization, influenza vaccine, subunit vaccine, split virus vaccine

\section{Introduction}

Many different technologies are currently used in the formulation of influenza vaccines. Split virus and subunit inactivated influenza vaccines, both consisting of disrupted virus particles, were some of the first technologies developed following early inactivated whole virus vaccines, which were developed in the 1940s (1). Split virus vaccines contain whole inactivated viruses that have been split with detergent, ether, or both, while subunit vaccines are made of purified hemagglutinin $(\mathrm{HA})$ and neuraminidase.

\author{
Affiliations \\ ${ }^{1} \mathrm{NACl}$ Influenza Working Group \\ Chair, Kingston, ON \\ ${ }^{2}$ Kingston, Frontenac and Lennox \\ \& Addington Public Health, \\ Kingston, ON \\ ${ }^{3}$ Centre for Immunization and \\ Respiratory Infectious Diseases, \\ Public Health Agency of Canada, \\ Ottawa, ON
}

\section{${ }^{\star}$ Correspondence: phac. naci-ccni.aspc@canada.ca}

Newer technologies and formulations for influenza vaccines have since been introduced, such as higher doses of antigen or combining the antigen with adjuvants; however, standard-dose subunit and split virus inactivated influenza vaccines (IIVs) are still the most commonly used seasonal influenza vaccines, as these vaccines have well-established safety profiles and are less expensive than newer formulations. A large number of the seasonal influenza vaccines available for use in Canada are standard-dose subunit or split virus IIVs (2). 
The National Advisory Committee on Immunization (NACl) has not previously critically appraised the evidence on the comparative vaccine effectiveness and immunogenicity of subunit versus split virus IIV in any age group. If one of the vaccine types was more effective, it would be important to know, particularly for older Canadian adults (65 years of age and older), who are at highest risk of influenza-related hospitalizations (3) and deaths (4). Older adults may also experience reduced vaccine effectiveness against influenza infection compared with younger age groups (5).

The primary objective of this literature review was to compare the vaccine effectiveness and immunogenicity of unadjuvanted, standard-dose subunit IIV versus unadjuvanted, standard-dose split virus IIV in adults 65 years of age and older. A full report is available online (6).

\section{Methods}

A rapid review methodology was used that was based on methods developed by Tricco et al. (7). The research question addressed in this review is as follows: Does the vaccine effectiveness, immunogenicity, or both of unadjuvanted, standard-dose subunit IIV differ from unadjuvanted, standard-dose split virus IIV among adults 65 years of age and older?

\section{A priori search strategy}

A search strategy was developed in consultation with a federal Reference Librarian, and included search terms for subunit influenza vaccine, split virus influenza vaccine, vaccine effectiveness and immunogenicity. The search was restricted to studies published in English or French, in EMBASE, MEDLINE and ClinicalTrials.gov databases published in 2007 or later.

\section{Inclusion and exclusion criteria}

Studies were included if they met the following criteria:

- the study directly or indirectly compares the vaccine effectiveness or immunogenicity of an unadjuvanted, standard-dose subunit IIV to an unadjuvanted, standard-dose split virus IIV;

- $\quad$ the study population is within the age range of interest (65 years of age and older).

Studies were excluded if they met one or more of the following criteria:

- the study does not present vaccine effectiveness or immunogenicity for both vaccine types of interest;

- the study is in a language other than English or French;

- the study is a non-human, in vivo or in vitro study;

- the article is an editorial, opinion or news report;

- the study presents only secondary research.

Screening and eligibility assessments were completed by a single reviewer.

\section{Data extraction, synthesis and quality assessment}

Data from included studies were extracted into evidence tables, defined a priori. The quality (internal validity) of included studies was assessed using criteria outlined by Harris et al. (8). Data extraction and quality assessment were completed by one reviewer and verified by a second reviewer. Results from included studies were synthesized narratively.

\section{Post-hoc modifications}

Due to the small number of records retrieved from the initial database search, search criteria were modified. The publication date restriction was removed, three additional databases were added (the Cochrane Central Register of Controlled Trials, Scopus and Web of Science) and, since a number of studies defined older adults as individuals 60 years of age and older but were otherwise eligible, the eligibility criteria were modified to include adults 60 years of age and older.

\section{Results}

The initial database search retrieved 30 records; only three of these studies met inclusion criteria. After post-hoc modifications, 41 unique studies were identified through the search and eight met the revised inclusion criteria (Figure 1). Three of the included studies reported on vaccine effectiveness, and five of the studies reported on immunogenicity. None of the identified studies compared quadrivalent with trivalent vaccine formulations of subunit or split virus IIVs. The study characteristics of the included studies are shown in Table 1 below.

Figure 1: Flow diagram for comparative effectiveness and immunogenicity of subunit and split virus IIVs in older adults: October 2017

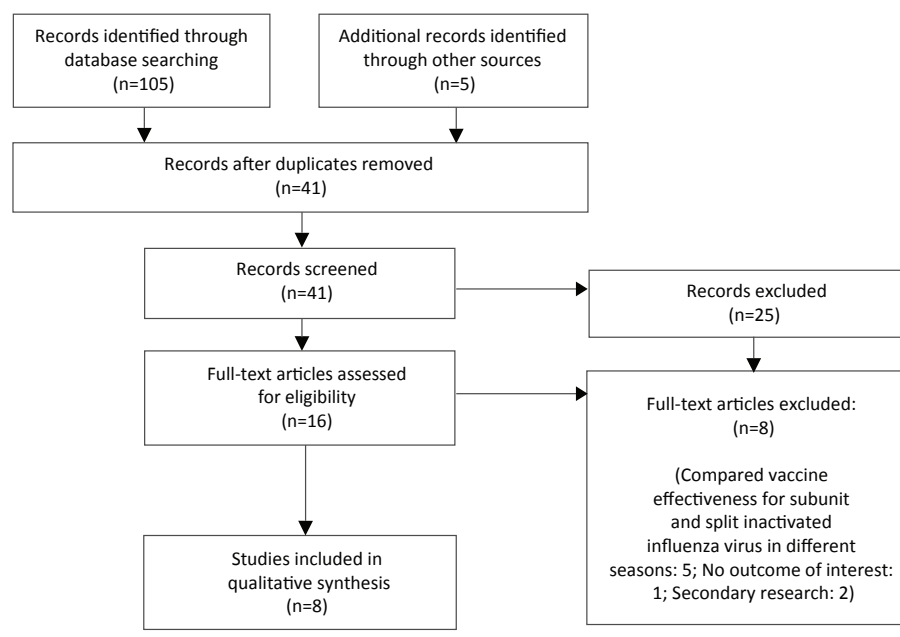

a Initial search October 13, 2017 and re-run with modifications on October 16, 2017

\section{Vaccine effectiveness}

Three of the included studies reported on the vaccine effectiveness of unadjuvanted, standard-dose subunit and split virus IIVs $(11,13,15)$, with only one study reporting a direct estimate for the difference in vaccine effectiveness between the two types of influenza vaccines (15). All three studies used test-negative case-control designs and all three were rated as "fair" according to criteria outlined by Harris et al. (8). None of the studies reported a significant difference in vaccine effectiveness between subunit IIV and split virus IIV against 
Table 1: Study characteristics of included studies

\begin{tabular}{|c|c|c|c|c|c|}
\hline Study & Location & Season & Design & Population & Outcome \\
\hline Camilloni, 2016 (9) & Italy & $\begin{array}{l}1988-1989 \text { to } \\
2014-2015\end{array}$ & Cohort & $\begin{array}{l}60 \text { years of age and } \\
\text { older }\end{array}$ & Immunogenicity \\
\hline Del Giudice, 2006 (10) & Not stated & 2003-2004 & Not stated & $\begin{array}{l}60 \text { years of age and } \\
\text { older }\end{array}$ & Immunogenicity \\
\hline Kissling, 2014 (11) & $\begin{array}{l}\text { Seven European } \\
\text { countries }\end{array}$ & 2012-2013 & $\begin{array}{l}\text { Test-negative } \\
\text { case-control }\end{array}$ & $\begin{array}{l}60 \text { years of age and } \\
\text { older }\end{array}$ & Vaccine effectiveness \\
\hline Morales, 2003 (12) & Colombia & 1999-2000 & $\mathrm{RCT}$ & $\begin{array}{l}60 \text { years of age and } \\
\text { older }\end{array}$ & Immunogenicity \\
\hline Rondy, 2017 (13) & 11 European countries & 2015-2016 & $\begin{array}{l}\text { Test-negative } \\
\text { case-control }\end{array}$ & $\begin{array}{l}65 \text { years of age and } \\
\text { older }\end{array}$ & Vaccine effectiveness \\
\hline Skowronski, 2012 (14) & Canada & 2011-2012 & $\mathrm{RCT}$ & $\begin{array}{l}65 \text { years of age and } \\
\text { older }\end{array}$ & Immunogenicity \\
\hline Talbot, 2015 (15) & United States & $\begin{array}{l}\text { 2008-2009, 2010-2011, } \\
\text { and 2011-2012 }\end{array}$ & $\begin{array}{l}\text { Test-negative } \\
\text { case-control }\end{array}$ & $\begin{array}{l}50 \text { years of age and } \\
\text { older (subpopulation: } 65 \\
\text { years of age and older) }\end{array}$ & Vaccine effectiveness \\
\hline Zei, 1991 (16) & Italy & 1989-1990 & $\mathrm{CCT}$ & $\begin{array}{l}60 \text { years of age and } \\
\text { older }\end{array}$ & Immunogenicity \\
\hline
\end{tabular}

Abbreviations: CCT, clinical controlled trial; RCT, randomized controlled trial

any laboratory-confirmed influenza virus strain $(11,15)$, against influenza $A(H 1 N 1), A(H 3 N 2)$ or $B$ virus specifically $(11,15)$, or against hospitalization due to influenza (13).

\section{Immunogenicity}

Five studies were identified that reported on the immunogenicity of subunit and split virus trivalent influenza vaccines (TIVs) $(9,10,12,14,16)$. Of these studies, only two reported a direct comparison between the two types of vaccines $(9,16)$. Three of the five studies were evaluable by Harris et al. criteria $(9,12,16)$, of which one received a "fair" rating (12) and two received "poor" ratings $(9,16)$. The two other studies did not report study methodology in sufficient detail to assess study quality $(10,14)$. The immunogenicity outcomes assessed by the identified studies included geometric mean fold rise in HA titres (i.e., ratio of post- to pre-vaccination geometric mean titre), seroprotection rate (i.e., proportion of participants with $\mathrm{HA}$ titres of at least 40 post-vaccination) and seroconversion rate (i.e., proportion of participants with at least a four-fold increase in HA titres post-vaccination, HA titre increase from less than 10 pre-vaccination to at least 40 post-vaccination, or both). Four studies assessed protection against the influenza virus strains contained within the vaccines. Two studies reported direct comparisons of immunogenicity measures $(9,16)$ and two reported indirect comparisons $(10,12)$. Overall, the studies showed no consistent significant differences in geometric mean fold rise, seroprotection rate or seroconversion rate between split virus IIVs and subunit IIVs against influenza $A(H 1 N 1)$, $\mathrm{A}(\mathrm{H} 3 \mathrm{~N} 2)$ or $\mathrm{B}$. In addition, two studies indirectly assessed cross-protection against variant influenza strains $(10,14)$. Neither of these studies found a significant difference in geometric mean fold rise, seroprotection rate or seroconversion rate between split virus IIVs and subunit IIVs.

\section{Discussion}

The overall quality of vaccine effectiveness evidence was fair, with one study reporting a direct vaccine effectiveness estimate and two studies reporting an indirect vaccine effectiveness estimate. The reported vaccine effectiveness estimates for split virus IIVs and subunit IIVs all had widely overlapping confidence intervals; however, without a direct comparison, it is difficult to draw firm conclusions on the comparative vaccine effectiveness of the two vaccines types. The authors of one of these studies also noted that there were likely important differences between study sites that were not controlled for, and that any comparisons between vaccine effectiveness of subunit IIV and split virus IIV should be interpreted with caution (13).

Findings from the studies that reported on immunogenicity were not consistent, and the overall quality of immunogenicity evidence was weak. All studies had at least one serious concern, the most common being the comparability between intervention groups. Two studies did not provide enough information to evaluate their quality $(10,14)$. Also, all included studies assessed immunogenicity by hemagglutination inhibition assay. These assays assess antibody as opposed to cell-mediated response, but the latter has been shown to be a more robust correlation of protection in older adults (17). In addition, the amount of HA antigen in unadjuvanted, standard-dose subunit IIVs and split virus IIVs is standardized; therefore, HA antibody titres may not be an appropriate measure of immunogenicity to answer this research question.

\section{Limitations}

Due to the small number of records returned by the initial database search, post-hoc protocol modifications were made that were more consistent with a traditional systematic review than the initial rapid review protocol; however, screening was still conducted by a single reviewer. A study by Edwards et al. found that study selection involving only one reviewer missed an average of $8 \%$ of eligible studies compared with study selection involving two reviewers (18); therefore, some studies may have been erroneously excluded. The impact that this factor would have on the conclusions drawn from a rapid review are still unclear. In addition, it is possible that the database search strategy missed some studies that examined vaccine effectiveness or immunogenicity by vaccine type in sub-analyses or as a secondary outcome; however, hand searching reference lists would help mitigate the number of eligible articles of this type that may have been excluded by the search criteria. 
Another important limitation of this review is that many of the included studies defined older adults as participants who were 60 years of age and older. The inclusion of adults 60 to 64 years of age may lead to greater healthy vaccinee bias, as adults in this age range on average may be healthier than adults 65 years of age and older; therefore, estimates from these studies should be interpreted with caution in the Canadian context, where older individuals are commonly defined as adults 65 years of age and older.

\section{Conclusion}

The $\mathrm{NACl}$ concludes that there is insufficient evidence to determine significant differences in the vaccine effectiveness or immunogenicity of unadjuvanted, standard-dose subunit and split virus IIVs in adults 65 years of age and older (Grade I evidence). The evidence is inconsistent and is not of sufficient quantity or quality to make specific recommendations on the differential use of unadjuvanted, standard-dose subunit and split virus IIVs in older adults.

\section{Authors' statement}

IG - Writing - original draft, writing - review and editing KY - Writing - original draft, writing - review and editing

The NACl Literature Review on the Comparative Effectiveness and Immunogenicity of Subunit and Split Virus Inactivated Influenza Vaccines in Adults 65 Years of Age and Older was prepared by K Young, L Zhao, R Stirling and MK Doll and approved by $\mathrm{NACl}$.

\section{Conflict of interest}

None.

\section{Acknowledgements}

Influenza Working Group Members: I Gemmill (Chair), C Bancej, L Cochrane, N Dayneka, L Grohskopf, G Jayaraman, D Kumar, J Langley, M Lavoie, J McElhaney, A McGeer, D Moore, B Warshawsky and J Xiong

NACI Members: C Quach (Chair), W Vaudry (Vice-Chair), N Dayneka, S Deeks, P DeWals, V Dubey, R Harrison, M Lavoie, C Rotstein, M Salvadori, B Sander, N Sicard and R Warrington

Liaison Representatives: J Brophy (Canadian Association for Immunization Research and Evaluation), E Castillo (Society of Obstetricians and Gynaecologist of Canada), A Cohn (Centres for Disease Control and Prevention, United States), T Cole (Canadian Immunization Committee), J Emili (College of Family Physicians of Canada), K Klein (Council of Chief Medical Officers of Health), C Mah (Canadian Public Health Association), D Moore (Canadian Paediatric Society) and A Pham-Huy (Association of Medical Microbiology and Infectious Disease Canada)

Ex-Officio Representatives: K Barnes (National Defence and the Canadian Armed Forces), G Charos (Centre for Immunization and
Respiratory Infectious Diseases [CIRID], Public Health Agency of Canada [PHAC]), G Coleman (Biologics and Genetic Therapies Directorate, Health Canada [HC]), J Gallivan (Marketed Health Products Directorate, HC), G Poliquin (National Microbiology Laboratory, PHAC), J Pennock (CIRID, PHAC) and T Wong (First Nations and Inuit Health Branch, HC)

The $\mathrm{NACl}$ gratefully acknowledges the contribution of L Glandon, A House, M Laplante, K Moncion and T Museau to the literature review.

\section{Funding}

The National Advisory Committee on Immunization work is supported by the Public Health Agency of Canada.

\section{References}

1. Krammer F, Palese P. Advances in the development of influenza virus vaccines. Nat Rev Drug Discov 2015 Mar;14(3):167-82. http://dx.doi.org/10.1038/nrd4529 PubMed (https://www.ncbi.nlm.nih.gov/pubmed/25722244)

2. National Advisory Committee on Immunization (NACl). Canadian Immunization Guide Chapter on Influenza and Statement on Seasonal Influenza Vaccine for 2017-2018. Public Health Agency of Canada 2017 https://www.canada. $\mathrm{ca} / \mathrm{fr} /$ sante-publique/services/publications/vie-saine/ guide-canadien-immunisation-declaration-vaccinationantigrippale-2017-2018.html

3. Schanzer DL, McGeer A, Morris K. Statistical estimates of respiratory admissions attributable to seasonal and pandemic influenza for Canada. Influenza Other Respir Viruses. 2013;7(5):799-808. http://dx.doi.org/10.1111/irv.12011 PubMed (https://www.ncbi.nlm.nih.gov/pubmed/23122189)

4. Schanzer DL, Sevenhuysen C, Winchester B, Mersereau T. Estimating influenza deaths in Canada, 1992-2009. PloS one. 2013;8(11):e80481. https://doi.org/10.1371/journal. pone.0080481 PubMed (https://www.ncbi.nlm.nih.gov/ pubmed/24312225)

5. Goodwin K, Viboud C, Simonsen L. Antibody response to influenza vaccination in the elderly: a quantitative review. Vaccine 2006 Feb;24(8):1159-69. http://dx.doi.org/10.1016/j. vaccine.2005.08.105. PubMed (https://www.ncbi.nlm.nih.gov/ pubmed/16213065)

6. Advisory committee review, National Advisory Committee on Immunization (NACl). Literature review update on the efficacy and effectiveness of high-dose (Fluzone ${ }^{\circledR}$ High-Dose) and MF59-adjuvanted (Fluad®) trivalent inactivated influenza vaccines in adults 65 years of age and older. Public Health Agency of Canada 2018 May. http://publications.gc.ca/site/ eng/9.852907/publication.html

7. Tricco AC, Zarin W, Antony J, Hutton B, Moher D, Sherifali $D$, Straus SE. An international survey and modified Delphi approach revealed numerous rapid review methods. J Clin Epidemiol 2016 Feb;70:61-7. http://dx.doi.org/10.1016/j. jclinepi.2015.08.012. PubMed (https://www.ncbi.nlm.nih.gov/ pubmed/26327490)

8. Harris RP, Helfand M, Woolf SH, Lohr KN, Mulrow CD, Teutsch SM, Atkins D, Methods Work Group, Third US Preventive Services Task Force. Current methods of the US Preventive Services Task Force: a review of the process. Am J Prev Med 


\section{REVIEW}

2001 Apr;20(3 Suppl):21-35. http://dx.doi.org/10.1016/ S0749-3797(01)00261-6. PubMed (https://www.ncbi.nlm.nih. gov/pubmed/11306229)

9. Camilloni B, Nunzi E, Basileo M, lorio AM. Steps Forwards in Diagnosing and Controlling Influenza. INTECH. 2016:215237. ed. Manal Mohammad Baddour. Chapter 10, Antibody responses after influenza vaccination in elderly people: Useful information from a 27-year study (from 1988-1989 to 20142015). http://dx.doi.org/10.5772/64405

10. Del Giudice G, Hilbert AK, Bugarini R, Minutello A, Popova O, Toneatto D, Schoendorf I, Borkowski A, Rappuoli R, Podda A. An MF59-adjuvanted inactivated influenza vaccine containing A/Panama/1999 (H3N2) induced broader serological protection against heterovariant influenza virus strain $\mathrm{A} /$ Fujian/2002 than a subunit and a split influenza vaccine. Vaccine 2006 Apr;24(16):3063-5. http://dx.doi.org/10.1016/j. vaccine.2006.01.015. PubMed (https://www.ncbi.nlm.nih.gov/ pubmed/16464520)

11. Kissling E, Valenciano M, Buchholz U, Larrauri A, Cohen JM, Nunes B, Rogalska J, Pitigoi D, Paradowska-Stankiewicz I, Reuss A, Jiménez-Jorge S, Daviaud I, Guiomar R, O'Donnell J, Necula G, Głuchowska M, Moren A. Influenza vaccine effectiveness estimates in Europe in a season with three influenza type/subtypes circulating: the I-MOVE multicentre case-control study, influenza season 2012/13. Euro Surveill 2014 Feb;19(6):20701. http://dx.doi.org/10.2807/1560-7917. ES2014.19.6.20701. PubMed (https://www.ncbi.nlm.nih.gov/ pubmed/24556348)

12. Morales A, Arias Salazar J, Salazar Y, García A, Arnoux S, Arancibia A, Deroche C, Rey E. A randomized controlled trial comparing split and subunit influenza vaccines in adults in Colombia. Medicina (B Aires) 2003;63(3):197-204. PubMed (https://www.ncbi.nlm.nih.gov/pubmed/12876902)

13. Rondy M, Larrauri A, Casado I, Alfonsi V, Pitigoi D, Launay $O$, Syrjänen RK, Gefenaite G, Machado A, Vucina WV, Horváth JK, Paradowska-Stankiewicz I, Marbus SD, Gherasim A, Díaz-González JA, Rizzo C, Ivanciuc AE, Galtier F, Ikonen N, Mickiene A, Gomez V, Kurecic Filipovic S, Ferenczi A, Korcinska
MR, van Gageldonk-Lafeber R, I-MOVE+ hospital working group, Valenciano M. 2015/16 seasonal vaccine effectiveness against hospitalisation with influenza $A(\mathrm{H} 1 \mathrm{~N} 1) p d m 09$ and $B$ among elderly people in Europe: results from the I-MOVE+ project. Euro Surveill 2017 Jul;22(30):30580. http://dx.doi. org/10.2807/1560-7917.ES.2017.22.30.30580. PubMed (https://www.ncbi.nlm.nih.gov/pubmed/28797322)

14. Skowronski DM, Janjua NZ, De Serres G, Purych D, Gilca V, Scheifele DW, Dionne M, Sabaiduc S, Gardy JL, Li G, Bastien N, Petric M, Boivin G, Li Y. Cross-reactive and vaccine-induced antibody to an emerging swine-origin variant of influenza A virus subtype H3N2 (H3N2v). J Infect Dis 2012 Dec;206(12):1852-61. https://doi.org/10.1093/infdis/jis500. PubMed (https://www.ncbi.nlm.nih.gov/pubmed/22872731)

15. Talbot HK, Nian H, Zhu Y, Chen Q, Williams JV, Griffin MR. Clinical effectiveness of split-virion versus subunit trivalent influenza vaccines in older adults. Clin Infect Dis 2015 Apr;60(8):1170-5. http://dx.doi.org/10.1093/cid/civ019. PubMed (https://www.ncbi.nlm.nih.gov/pubmed/25697739)

16. Zei T, Neri M, lorio AM. Immunogenicity of trivalent subunit and split influenza vaccines (1989-90 winter season) in volunteers of different groups of age. Vaccine 1991 Sep;9(9):613-7. http://dx.doi.org/10.1016/0264410X(91)90184-8. PubMed (https://www.ncbi.nlm.nih.gov/ pubmed/1950094)

17. McElhaney JE, Xie D, Hager WD, Barry MB, Wang Y, Kleppinger A, Ewen C, Kane KP, Bleackley RC. T cell responses are better correlates of vaccine protection in the elderly. J Immunol 2006 May;176(10):6333-9. http://dx.doi. org/10.4049/jimmunol.176.10.6333. PubMed (https://www. ncbi.nlm.nih.gov/pubmed/16670345)

18. Edwards P, Clarke M, DiGuiseppi C, Pratap S, Roberts I, Wentz R. Identification of randomized controlled trials in systematic reviews: accuracy and reliability of screening records. Stat Med 2002 Jun;21(11):1635-40. http://dx.doi. org/10.1002/sim.1190. PubMed (https://www.ncbi.nlm.nih. gov/pubmed/12111924) 